\title{
uPA is upregulated by high dose celecoxib in women at increased risk of developing breast cancer
}

Wenyi Qin ${ }^{1}$, Weizhu Zhu' ${ }^{1}$, John E Hewett ${ }^{2}$, George Rottinghaus ${ }^{3}$, YinChieh Chen ${ }^{3}$, John T Flynn ${ }^{4}$, Beth Kliethermes ${ }^{1}$, Ferdinando Mannello ${ }^{5,6}$ and Edward R Sauter*1

Address: ${ }^{1}$ Department of Surgery, University of North Dakota, Grand Forks, ND, USA, ${ }^{2}$ Departments of Biostatistics, University of Missouri, Columbia, MO, USA, ${ }^{3}$ Veterinary Medical Diagnostics, University of Missouri, Columbia, MO, USA, ${ }^{4}$ Institute of Histology and Laboratory Analysis, Thomas Jefferson University, Philadelphia, PA, USA, ${ }^{5}$ Department of Physiology, Thomas Jefferson University, Philadelphia, PA, USA and "University "Carlo Bo", Urbino 61029, Italy

Email: Wenyi Qin -wqin@medicine.nodak.edu; Weizhu Zhu - wzhu@medicine.nodak.edu; John E Hewett - hewettj@health.missouri.edu; George Rottinghaus - rottinghausg@missouri.edu; Yin-Chieh Chen - yinchieh_chen@yahoo.com; John T Flynn - john.flynn@jefferson.edu; Beth Kliethermes - bkliethermes@medicine.nodak.edu; Ferdinando Mannello - ferdinando.mannello@uniurb.it;

Edward R Sauter* - esauter@medicine.nodak.edu

* Corresponding author

Published: 15 October 2008

BMC Cancer 2008, 8:298 doi:10.1 I86/147|-2407-8-298

This article is available from: http://www.biomedcentral.com/147/-2407/8/298

(C) 2008 Qin et al; licensee BioMed Central Ltd.

This is an Open Access article distributed under the terms of the Creative Commons Attribution License (http://creativecommons.org/licenses/by/2.0), which permits unrestricted use, distribution, and reproduction in any medium, provided the original work is properly cited.

\begin{abstract}
Background: While increased urokinase-type plasminogen activator (uPA) expression in breast cancer tissue is directly associated with poor prognosis, recent evidence suggests that uPA overexpression may suppress tumor growth and prolong survival. Celecoxib has been shown to have antiangiogenic and antiproliferative properties. We sought to determine if uPA, PA inhibitor (PAI)-I and prostaglandin (PG) $\mathrm{E}_{2}$ expression in nipple aspirate fluid (NAF) and $\mathrm{uPA}$ and $\mathrm{PGE}_{2}$ expression in plasma were altered by celecoxib dose and concentration in women at increased breast cancer risk.
\end{abstract}

Methods: NAF and plasma samples were collected in women at increased breast cancer risk before and 2 weeks after taking celecoxib 200 or 400 mg twice daily (bid). UPA, PAI-I and PGE were measured before and after intervention.

Results: Celecoxib concentrations trended higher in women taking $400 \mathrm{mg}$ (median $1025.0 \mathrm{ng} / \mathrm{mL}$ ) compared to $200 \mathrm{mg}$ bid (median $227.3 \mathrm{ng} / \mathrm{mL}$ ), and in post- $(534.6 \mathrm{ng} / \mathrm{mL}$ ) compared to premenopausal $(227.3 \mathrm{ng} / \mathrm{mL}$ ) women. In postmenopausal women treated with the higher $(400 \mathrm{mg}$ bid) celecoxib dose, UPA concentrations increased, while PAI-I and $\mathrm{PGE}_{2}$ decreased. In women taking the higher dose, both PAI-I $(r=-.97, \mathrm{P}=.0048)$ and $\mathrm{PGE}_{2}(r=-.69, \mathrm{p}=.019)$ in NAF and uPA in plasma $(r=.45, P=.023)$ were correlated with celecoxib concentrations.

Conclusion: Celecoxib concentrations after treatment correlate inversely with the change in PAI$I$ and $P G E_{2}$ in the breast and directly with the change in uPA in the circulation. uPA upregulation, in concert with PAI-I and $\mathrm{PGE}_{2}$ downregulation, may have a cancer preventive effect. 


\section{Background}

Cancer cell invasion and metastasis requires the degradation of the extracellular matrix (ECM) and basement membrane. This process is accomplished by several proteins, including those of the plasminogen activator (PA) system. Urokinase-type PA (uPA), which is secreted in inactive form (pro-uPA), plays a key role in ECM degradation. Pro-uPA is converted to its active form after binding to its specific surface receptor, uPAR $[1,2]$. In women with breast cancer, UPA appears to promote cancer invasion and metastasis [3] through degradation of the ECM, stimulation of angiogenesis, alteration in cell migration and adhesion [4], and inhibition of apoptosis [5].

The total involvement of plasminogen activators in cancer, however, is not that clear. In addition to demonstrated negative effects, PAs apparently play a positive role in certain aspects of the cancer process. For example, PAs induce antiangiogenic activity in vitro and in patients with cancer [6]. Several clinical studies have shown associations between high tissue-type PA expression and activity and a favorable prognosis in breast cancer [7]. In a mouse mammary cancer model, induced uPA expression delayed tumor progression and had antiangiogenic and antiproliferative effects. Tumors expressing proteolytically inactive uPA mutants grew faster than tumors overexpressing proteolytically active UPA, suggesting that the inhibitory actions were mediated by uPA's protease activity [8].

Plasminogen activator activity is inhibited by plasminogen activator inhibitor-1 (PAI-1) [9]. While uPA has both positive and negative actions in cancer, PAI-1 promotes breast cancer invasion and metastasis. Deficient PAI-1 expression in mice prevented local invasion and tumor vascularization of transplanted malignant keratinocytes. When PAI-1 expression was restored, invasion and associated angiogenesis were also restored, suggesting that hostproduced PAI-1 is essential for cancer cell invasion and angiogenesis [10]. PAI-1 promotes angiogenesis by directly inhibiting proteases [11], suggesting that excessive plasmin proteolysis may prevent the assembly of tumor blood vessels. Possible mechanisms by which PAI1 promotes breast cancer include prevention of excess ECM degradation, modulation of cell adhesion, a role in angiogenesis, and the stimulation of cell proliferation [3]. It therefore appears that the association of UPA and PAI-1 expression with breast cancer is complex.

Two hypotheses proposed for the effects of PAs on tumor invasiveness [8] are that enhanced proteolytic activity of uPA may result in cleavage of tumor stromal proteins into peptides that inhibit angiogenesis and/or proliferation, or that plasmin generated by uPA activity activates other stromal proteases, leading to tumor matrix disruption.
Celecoxib is an anti-inflammatory agent known to have antiangiogenic [12] and antiproliferative properties [13]. The agent has been shown to prevent [14] and treat mammary tumors in animal models [15]. We observed that celecoxib blocks prostaglandin $(\mathrm{PG}) \mathrm{E}_{2}$ in high risk women and in women with breast cancer [16]. Celecoxib has been reported to inhibit uPA production in MDA-MB231 breast cancer cells [17].

We previously reported that $\mathrm{PGE}_{2}$, a small lipid associated with breast tumor development, decreased in proportion to circulating celecoxib concentration in postmenpausal women taking the $400 \mathrm{mg}$ twice daily (bid) dose [18]. Our previous experience using celecoxib to inhibit eicosanoid production, the fact that celecoxib affects uPA production and the conflicting findings regarding the role of uPA and PAI-1 in tumor progression caused us to investigate the expression of UPA and PAI- 1 in the breast and UPA systemically before and after treatment with low (200 mg bid) and high (400 mg bid) dose celecoxib.

\section{Methods}

\section{Subject recruitment}

Between October 2001 and December 2004, women were provided an Institutional Review Board approved protocol and required to give written informed consent in order to enroll in the study. Subjects enrolled during the first half of the study received $200 \mathrm{mg}$ celecoxib bid, and those enrolled during the second half received $400 \mathrm{mg}$ bid. Subjects evaluated had to be $\geq 18$ years old and be at increased breast cancer risk, based on the subject having either a Gail model risk of developing IBC in a 5 year period of > $1.66 \%$, or previously treated DCIS or IBC (now finished with treatment and free of disease).

Pregnant and lactating women were not eligible. Women could not have been currently on nonsteroidal antiinflammatory drugs (NSAIDs), a cyclo-oxygenase-2 (COX2) inhibitor, warfarin, or have taken such a medication within two weeks of enrollment. Subjects could not have a significant history of peptic ulcer disease, upper gastrointestinal bleeding, asthma, or be allergic to sulfonamides or NSAIDs. A complete blood count, serum electrolytes and liver panel performed within two months of enrollment had to be within normal limits. Subjects were recruited from the breast evaluation clinics at the University of Missouri-Columbia.

\section{Intervention}

Celecoxib pills were taken for 14 days. The treatment period was chosen to be short enough to maximize compliance yet long enough to see a biomarker effect, based on celecoxib's half life of 11 hours. Compliance was assessed through the count of returned pills. All subjects 
were required to have taken at least $80 \%$ of the prescribed medication.

\section{Specimen collection}

NAF was collected using a modified breast pump as previously described $[19,20]$. Briefly, the breast was warmed with moist heated towels for 5-10 minutes, subsequently massaged from the chest wall toward the nipple while a health care professional provided suction using a modified breast pump. The sample was collected into capillary tubes and stored at $-80^{\circ} \mathrm{C}$ until analysis. NAF volume was measured using a metric ruler. We have determined that one $\mathrm{mm}$ in the tube corresponds to approximately one $\mu \mathrm{L}$ of NAF. NAF was collected from only one breast, and NAF from the same breast was analyzed before and after treatment.

Baseline NAF and blood collection were performed prior to the ingestion of celecoxib. Eight $\mathrm{mL}$ of blood were also collected from the subject in a tube containing heparin, the blood centrifuged for $10 \mathrm{~min}$ at $1600 \mathrm{rpm}$, and the plasma fraction decanted and stored at $-80^{\circ} \mathrm{C}$ until analysis. All women had NAF and plasma collected within 24 hrs of their last dose of celecoxib, with an average of approximately $12 \mathrm{hrs}$. The half life of the medication is $11.5 \mathrm{hrs}$.

\section{Specimen analysis uPA and PAI-I}

uPA and PAI-1 enzyme linked immunosorbant assay kits were obtained from American Diagnostica, Inc. (Stamford, CT). uPA and UPAI-1 levels were determined according to the kit manufacturer's instructions. Briefly, $100 \mu \mathrm{L}$ of standard and samples were pipetted into the microplate wells that were coated with mouse monoclonal antibodies respectively specific for UPA and PAI- 1 and incubated overnight at $4{ }^{\circ} \mathrm{C}$. A washing procedure was performed 4 times to remove unbound proteins with washing buffer. Enzyme-linked antibodies specific for each factor were added to the wells and incubated for $1 \mathrm{~h}$ at room temperature. The wells were washed again, $100 \mu \mathrm{L}$ diluted enzyme conjugate (streptavidin conjugated horseradish peroxidase) was pipetted into wells and incubated for $1 \mathrm{~h}$ at room temperature, then washed again. Substrate reagent $(100 \mu \mathrm{L})$ was added to each well and incubated for 1 $\mathrm{h}$ at room temperature, followed by a stop solution $(0.5 \mathrm{~N}$ sulfuric acid). Absorbance values were measured at 450 $\mathrm{nm}$ for uPA and UPAI-1 using a microplate reader. The detection limits were $10 \mathrm{pg} / \mathrm{mL}$ for uPA and $125 \mathrm{pg} / \mathrm{mL}$ for PAI-1. To standardize UPA and PAI-1 expression in NAF, total protein was measured for each sample with a BCA protein assay kit (Pierce Chemicals, Rockford, IL), and results reported as pg of UPA or PAI-1 per mg total NAF protein.
$P G E_{2}$

NAF and plasma samples were analyzed by immunoassay for their $\mathrm{PGE}_{2}$ content as per the manufacturer's instructions (R\&D Systems, Minneapolis, MN). The kit uses a monoclonal antibody to $\mathrm{PGE}_{2}$ to competitively bind the $\mathrm{PGE}_{2}$ in the standard or sample. Briefly, samples were diluted in $100 \mu \mathrm{L}$ assay buffer supplied by the manufacturer, pipetted into appropriate wells, incubated for 18-24 hrs at $4^{\circ} \mathrm{C}$, washed, substrate solution added, followed by $1 \mathrm{hr}$ incubation, and absorbance measured at $405 \mathrm{~nm}$.

A standard curve was prepared using serial dilutions of $\mathrm{PGE}_{2}$. A linear regression equation was created from standards of known $\mathrm{PGE}_{2}$ concentration, and $\mathrm{PGE}_{2}$ concentrations of unknown samples fit to the standard curve regression equation, corrected for aliquot volume and expressed as nanograms of $\mathrm{PGE}_{2} / \mathrm{mL}$ of original sample. Whenever possible, NAF and plasma samples were run in duplicate and the average of the two values was reported. The goodness of fit of the standard curve, $\mathrm{R}^{2}$, for NAF samples was 0.999. The goodness of fit was similar for the plasma samples.

\section{Celecoxib}

Celecoxib was analyzed in plasma using a modification of the technique of Schonberger et al. [21] by combining 250 $\mu \mathrm{L}$ aliquots of plasma with an equal volume of distilled water and adding $500 \mu \mathrm{L}$ ethanol to precipitate the protein. Spiked plasma samples were prepared by combining $250 \mu \mathrm{L}$ blank plasma with $250 \mu \mathrm{l}$ distilled water, $20 \mu \mathrm{L}$ of 10 ppm celecoxib in ethanol and $480 \mu \mathrm{L}$ of ethanol. Samples were vortexed and then centrifuged at 13,000 rpm for $5 \mathrm{~min}$. A $500 \mu \mathrm{L}$ aliquot of the supernatant was combined with $1.5 \mathrm{~mL}$ distilled water and applied to a Waters $3 \mathrm{~mL}$ $\mathrm{C}_{18}$ Sep-Pac-Vac disposable cleanup column (Waters, Milford, MA) which was preconditioned with $2 \mathrm{~mL}$ methanol and then $2 \mathrm{~mL}$ distilled water. Cleanup columns were washed with $2 \mathrm{~mL}$ distilled water and vacuum dried for 15 minutes. Celecoxib was eluted with $4 \mathrm{~mL}$ methanol and the sample eluants taken to dryness. Samples were reconstituted in $1.0 \mathrm{~mL}$ methanol:water (80:20) for HPLC analysis.

HPLC analysis was performed on an Hitachi HPLC system (Hitachi Instruments, Inc., San Jose, CA) which consisted of an L7100 pump, with an L7200 autosampler (20 ul injected), and fluorescence detection with an L7480 fluorescence detector (excitation $240 \mathrm{~nm}$, emission $380 \mathrm{~nm}$ ). The system was controlled, data acquired and processed using an Hitachi D-7000 data acquisition package with Concert Chrom software on a microcomputer. A Phenomenex Hypersil BDS $\mathrm{C}_{18}$ analytical column $(250 \times 4.6 \mathrm{~mm}$, $5 \mathrm{um}$ ) (Phenomenex, Torrence, CA) and a Phenomenex Securityguard $\mathrm{C}_{18}$ precolumn with a mobile phase of ace- 
tonitrile:water (70:30) was used at a flow rate of $1 \mathrm{~mL} /$ min. Celecoxib was kindly provided by Pfizer Corporation, New York, NY. A primary standard of celecoxib $(2,000 \mathrm{ppm})$ was prepared in acetonitrile. Working standards $(100,200,500 \mathrm{ppb})$ were prepared in methanol:water (80:20). Plasma samples spiked with celecoxib had recoveries greater than $95 \%$.

\section{Toxicity}

Among women taking celecoxib $200 \mathrm{mg}$ bid, two subjects experienced side effects (one nausea, the second a cough), with both resolving spontaneously. There were no dropouts in the $200 \mathrm{mg}$ bid group. Among women enrolled in the $400 \mathrm{mg}$ bid group, 11 experienced side effects from celecoxib, four of whom dropped out. Of the four who dropped out, the side effects (edema in two, diarrhea in one, and heart palpitations in one) resolved shortly after stopping celecoxib. Among the remaining seven subjects, the side effects: diarrhea, nausea, rash, altered taste, urinary urgency, sweating, and muscle tension, all resolved spontaneously.

\section{Statistical analysis}

Median values of continuous variables were computed for the various groups of subjects. Due to the potential nonnormality of the data, ranking procedures were used for all analyses with continuous variables. The Wilcoxon Rank Sum Test was used to compare independent groups. Examples of these comparisons include comparing preand postmenopausal women. The Wilcoxon Signed Rank Test was used to make within group comparisons such as comparing pre treatment to post treatment.

We are interested in the change which occurs from pre to post treatment. Because of the potential skewness of the data, we report medians rather than means. The delta $(\Delta)$ reported in Table 2 is the median of the post - pre treatment differences. It should be noted that the median of these differences is seldom equal to the difference (post pre) in the medians. Thus, the $\Delta$ reported in Table 2 could be negative and the difference in the medians positive.

Table 2: Median concentrations in NAF of uPA and PAI-I (pg/mg), PGE 2 (ng/mL) and in plasma of celecoxib (ng/mL) based on celecoxib dose and menopausal status'

\begin{tabular}{|c|c|c|c|c|c|c|}
\hline Dose & $\mathbf{N}$ & Baseline & After Tx & $\Delta$ & $P$ value & Celecoxib \\
\hline \multicolumn{7}{|l|}{200 mg bid² } \\
\hline \multicolumn{7}{|l|}{ uPA } \\
\hline Overall & 9 & 422.0 & 375.2 & -19.6 & 0.10 & 346.0 \\
\hline Premen & 2 & 133.6 & 130.1 & -3.5 & 0.50 & 231.8 \\
\hline Postmen & 7 & 645.1 & 402.4 & -57.0 & 0.22 & 728.2 \\
\hline \multicolumn{7}{|l|}{ PAI-I } \\
\hline Overall & 8 & 709.0 & 194.4 & -26.7 & 0.56 & 288.1 \\
\hline Premen & 2 & 2672 & $|82|$ & -850.8 & 0.99 & 231.8 \\
\hline Postmen & 6 & 709.0 & 194.4 & -26.7 & 0.99 & 479.1 \\
\hline \multicolumn{7}{|l|}{$\mathrm{PGE}_{2}$} \\
\hline Overall & 9 & 8.71 & 13.34 & -1.04 & 0.91 & 346.0 \\
\hline Premen & 2 & 25.45 & 25.96 & 0.52 & 0.99 & 231.8 \\
\hline Postmen & 7 & 8.71 & 9.80 & -1.04 & 0.81 & 728.2 \\
\hline \multicolumn{7}{|l|}{400 mg bid² } \\
\hline \multicolumn{7}{|l|}{ UPA } \\
\hline Overall & 11 & 372.6 & 321.6 & 22.0 & 0.46 & 184.0 \\
\hline Premen & 5 & 372.6 & 321.6 & 11.0 & 0.99 & 0 \\
\hline Postmen & 6 & 409.1 & 382.4 & 28.2 & 0.31 & 1141.8 \\
\hline \multicolumn{7}{|l|}{ PAI-I } \\
\hline Overall & 5 & 2401 & 827.8 & 0 & 0.62 & 156.8 \\
\hline Premen & 1 & 281.6 & 344.7 & 63.1 & - & 0 \\
\hline Postmen & 4 & 2416 & 1437 & -801.7 & 0.50 & 789.9 \\
\hline \multicolumn{7}{|l|}{$\mathrm{PGE}_{2}$} \\
\hline Overall & 11 & 12.32 & 13.45 & -1.77 & 0.96 & 184.2 \\
\hline Premen & 5 & 12.32 & 51.24 & 21.95 & 0.31 & 0 \\
\hline Postmen & 6 & 14.79 & 13.22 & -6.41 & 0.16 & 1141.8 \\
\hline
\end{tabular}

I: N: sample size; NAF: nipple aspirate fluid. NS: not significant. Units reflect pg uPA or PAI-I/mg total protein. $\Delta$ reflects the median of the change measured in each subject (after treatment value - before treatment value) due to treatment. Celecoxib level is from plasma collected after treatment.

2: Not all NAF samples were sufficient to analyze all proteins; bid: twice daily; premen: premenopausal; postmen: postmenopausal 


\section{Results \\ Subjects}

Of 42 women evaluated, 17 took celecoxib $200 \mathrm{mg}$ bid and 25 celecoxib $400 \mathrm{mg}$ bid. Matched (pre and post treatment) plasma was available from all subjects. Matched NAF was available for analysis from approximately half of the subjects. All subjects reported that they took over $80 \%$ of the pills they were administered (Table $1)$.

\section{Celecoxib concentrations in $\mathrm{ng} / \mathrm{mL}$}

At the end of treatment, celecoxib was detectable in the plasma of 14 of 17 participants (82\%) in the $200 \mathrm{mg}$ group, and 19 of 25 participants $(76 \%)$ in the $400 \mathrm{mg}$ group. The limit of detection of the assay was $100 \mathrm{ng} / \mathrm{mL}$. Of samples in which celecoxib was detectable, values ranged from 117.6 to $2281.2 \mathrm{ng} / \mathrm{mL}$ in the $200 \mathrm{mg}$ group and from 156.8 to $16403.1 \mathrm{ng} / \mathrm{mL}$ in the $400 \mathrm{mg}$ group. Levels trended $(\mathrm{p}=0.12)$ higher in women taking $400 \mathrm{mg}$ (median $1025.0 \mathrm{ng} / \mathrm{mL}$ ) compared to $200 \mathrm{mg}$ bid (median $227.3 \mathrm{ng} / \mathrm{mL}$ ), and in post- $(534.6 \mathrm{ng} / \mathrm{mL})$ compared to premenopausal $(227.3 \mathrm{ng} / \mathrm{mL})$ women $(\mathrm{p}=$ $0.13)$.

\section{uPA levels in postmenopausal women increase, while PAl- $I$ and PGE2 decrease, after treatment with high dose celecoxib}

We first evaluated the change in UPA, PAI-1 and PGE Con- $_{2}$ centration in the NAF of each participant after low and high dose celecoxib administration (Table 2). The delta $(\Delta)$ in Table 2 represents the median change due to celecoxib intervention. uPA trended downward with low dose and upward with high dose treatment. PAI-1 trended downward at both celecoxib doses. PGE $_{2}$ concentrations also tended to decrease overall at both doses of celecoxib but the values measured in premenopausal women were slightly increased. This coincided with relatively low plasma concentrations of celecoxib. The changes in uPA, PAI- 1 and PGE $_{2}$ were not significant at either dose for preor postmenopausal women.

Table I: Demographics

\begin{tabular}{ccc}
\hline & \multicolumn{2}{c}{ Celecoxib Dose } \\
& $\begin{array}{c}200 \mathrm{mg} \text { twice daily } \\
\text { NAF (plasma) }\end{array}$ & $\begin{array}{l}400 \mathrm{mg} \text { twice daily } \\
\text { NAF (plasma) }\end{array}$ \\
\hline $\begin{array}{c}\text { Samples } \\
\text { Age (years) } \\
\text { Median }\end{array}$ & $9(17)$ & $11(25)$ \\
Range & $23-67(23-68)$ & $51(50)$ \\
$\begin{array}{c}\text { Menopause } \\
\text { Pre }\end{array}$ & $2(4)$ & $30-68(30-81)$ \\
Post & $7(13)$ & $5(11)$ \\
& & $6(14)$
\end{tabular}

We next evaluated the change in plasma uPA and $\mathrm{PGE}_{2}$ concentration after low and high dose celecoxib administration (Table 3). PAI-1 was not evaluated in plasma due to inadequate samples available. Similar to NAF, uPA levels in plasma trended downward with low dose and upward with high dose treatment. Plasma $\mathrm{PGE}_{2}$ changed little after treatment, with a small move upward with low dose and downward move with high dose therapy. The change in neither uPA nor $\mathrm{PGE}_{2}$ was significant for either pre- or postmenopausal women.

\section{Effect of circulating celecoxib concentrations on biomarker change}

Considering subjects in both dosage groups, there was an inverse correlation between celecoxib concentration and change in NAF PGE $2(\mathrm{r}=-.42, \mathrm{p}=.06, \mathrm{n}=20)$ and plasma uPA $(\mathrm{r}=.38, \mathrm{p}=.012, \mathrm{n}=42)$ post treatment, which was not observed for the other markers. There were no significant associations between UPA, PAI- 1 or PGE P $_{2}$ in NF or plasma and celecoxib concentration in women receiving low dose celecoxib. In women taking the higher dose, both PAI-1 $(\mathrm{r}=-.97, \mathrm{p}=.0048, \mathrm{n}=5)$ and $\mathrm{PGE}_{2}(\mathrm{r}=-.69$, $\mathrm{p}=.019, \mathrm{n}=11)$ in NAF and uPA in plasma $(\mathrm{r}=.45, \mathrm{p}=$ $.023, \mathrm{n}=25)$ were correlated with celecoxib concentration (Figure 1).

\section{Discussion}

We carried out experiments to investigate whether the COX-2 inhibitor celecoxib at a dose of either $200 \mathrm{mg}$ bid or $400 \mathrm{mg}$ bid could significantly affect endogenous uPA, PAI-1 or PGE 2 production in women at increased risk for breast cancer. The same NAF and plasma samples were used to measure all three markers so that we could determine celecoxib's coordinate effect on them. This study builds on our initial study, which found that celecoxib $400 \mathrm{mg}$ bid decreased $\mathrm{PGE}_{2}$ levels in NAF and/or plasma in women with newly diagnosed breast cancer and in high risk women [16].

We previously observed that $\mathrm{UPA}$ and PAI- 1 are concentrated in NAF compared to plasma [22]. This fact, as well as the fact that NAF is breast specific, undiluted by the contribution from other organs, suggests that it may be a better physiologic fluid than plasma to identify breast cancer biomarkers.

uPA expression trended downward among women receiving the lower celecoxib dose and upward among those receiving the higher dose, suggesting a dose-dependent effect of the medication. Sample size may have limited our ability to detect a significant effect. The different uPA response was more noted in post- than in premenopausal women, in whom celecoxib concentrations tended to be higher. Similarly, we previously observed that high (but not low) dose celecoxib significantly decreased $\mathrm{PGE}_{2}$ lev- 
Table 3: Median concentrations in plasma of uPA (pg/mL), $\mathrm{PGE}_{2}(\mathrm{ng} / \mathrm{mL})$ and celecoxib $(\mathrm{ng} / \mathrm{mL})$ based on celecoxib dose and menopausal status 1

\begin{tabular}{|c|c|c|c|c|c|c|}
\hline Dose & $\mathbf{N}$ & Baseline & After Tx & $\Delta$ & P Value & Celecoxib \\
\hline \multicolumn{7}{|l|}{$200 \mathrm{mg}$ bid² $^{2}$} \\
\hline \multicolumn{7}{|l|}{ uPA } \\
\hline Overall & 17 & 941.4 & 955.0 & -20.7 & 0.85 & 233.7 \\
\hline Premen & 4 & 886.9 & 1031.8 & 36.0 & 0.62 & 195.3 \\
\hline Postmen & 13 & 994.0 & 945.6 & -20.7 & 0.64 & 233.7 \\
\hline \multicolumn{7}{|l|}{$\mathrm{PGE}_{2}$} \\
\hline Overall & 17 & 0.209 & 0.206 & 0.005 & 0.96 & 233.7 \\
\hline Premen & 4 & 0.244 & 0.221 & 0.100 & 0.99 & 0 \\
\hline Postmen & 13 & 0.204 & 0.195 & 0.005 & 0.84 & 233.7 \\
\hline \multicolumn{7}{|l|}{$400 \mathrm{mg} \mathrm{bid}^{2}$} \\
\hline \multicolumn{7}{|l|}{ UPA } \\
\hline Overall & 25 & 908.3 & 910.7 & 17.5 & 0.8 & 696.0 \\
\hline Premen & 11 & 864.9 & 821.0 & 17.5 & 0.8 & 227.3 \\
\hline Postmen & 14 & 1036.1 & 992.4 & 7.9 & 0.7 & 1024.9 \\
\hline \multicolumn{7}{|l|}{$\mathrm{PGE}_{2}$} \\
\hline Overall & 25 & 0.280 & 0.203 & -0.009 & 0.93 & 696.0 \\
\hline Premen & 11 & 0.375 & 0.366 & -0.001 & 0.77 & 227.2 \\
\hline Postmen & 14 & 0.280 & 0.175 & -0.023 & 0.90 & 1025.0 \\
\hline
\end{tabular}

I: N: sample size; NAF: nipple aspirate fluid. Units reflect $\mathrm{pg} u \mathrm{uA} / \mathrm{mL}$ plasma volume. $\Delta$ uPA reflects the median of the change measured in each subject (after treatment value - before treatment value) due to treatment. Celecoxib level is from plasma collected after treatment.

2: bid: twice daily; premen: premenopausal; postmen: postmenopausal.

els in post- but not premenopausal women, in whom higher circulating celecoxib levels were noted [16]. In the current study a similar trend was noted for $\mathrm{PGE}_{2}$. Sample size may have limited our ability to detect a significant effect.

Mice prone to the development of intestinal adenomas that were made deficient in uPA were found to upregulate COX-2 expression [23]. It has been shown that PAs generate endogenous angiogenesis inhibitors, and mice with tumors that overexpressed uPA demonstrated tumor growth inhibition, fewer lung metastases and prolonged survival compared to controls [8]. There is evidence that PAI-1, an inhibitor of UPA, may promote angiogenesis [10]. It was found that celecoxib was more effective than the combination of celecoxib plus the PA inhibitor amiloride in reducing the number of pulmonary metastases, with metastases suppressed by $67 \%$ with amiloride alone, $98 \%$ with celecoxib alone and $81 \%$ with the combined regimen. In our own subjects, medication dose provided hints as to the effect of celecoxib, but the effect was masked by individual differences in celecoxib metabolism. On the other hand, evaluating the circulating level of celecoxib demonstrated the effect of the agent, and consistent with preclinical reports discussed above, NAF levels of PAI-1 and $\mathrm{PGE}_{2}$ decreased in relation to increasing celecoxib concentrations, while uPA plasma levels increased in relation to increased circulating celecoxib (Figure 1).

\section{Conclusion}

Patients receiving celecoxib $200 \mathrm{mg}$ bid demonstrated decreased uPA concentrations in NAF and plasma whereas patients receiving celecoxib $400 \mathrm{mg}$ bid demonstrated increased concentrations of UPA in both NAF and plasma. PAI-1 was more decreased in the NAF of patients receiving the 200 compared to the $400 \mathrm{mg}$ bid celecoxib dose. $\mathrm{PGE}_{2}$ concentrations trended lower in both NAF and plasma after celecoxib treatment. PAI-1 and $\mathrm{PGE}_{2}$ decreased in NAF and uPA increased in plasma in relation to the circulating level of celecoxib, which may better reflect the action of the agent than dosage, since individuals metabolize celecoxib at different rates. These findings are consistent with animal studies which suggest that, unlike in subjects with invasive breast cancer (in whom high levels of UPA are associated with a poor prognosis [24]), in high risk women the upregulation of uPA (in association with downregulation of PAI-1 and $\mathrm{PGE}_{2}$ ) may have a breast cancer chemopreventive effect.

\section{Abbreviations}

bid: twice daily; COX: cyclooxygenase; ECM: extracellular matrix; HPLC: high performance liquid chromatography; NAF: nipple aspirate fluid; NSAIDs: nonsteroidal antiinflammatory drugs; PG: prostaglandin; PAI: prostaglandin inhibitor; uPA: urokinase-type plasminogen activator.

\section{Competing interests}

The authors declare that they have no competing interests. 

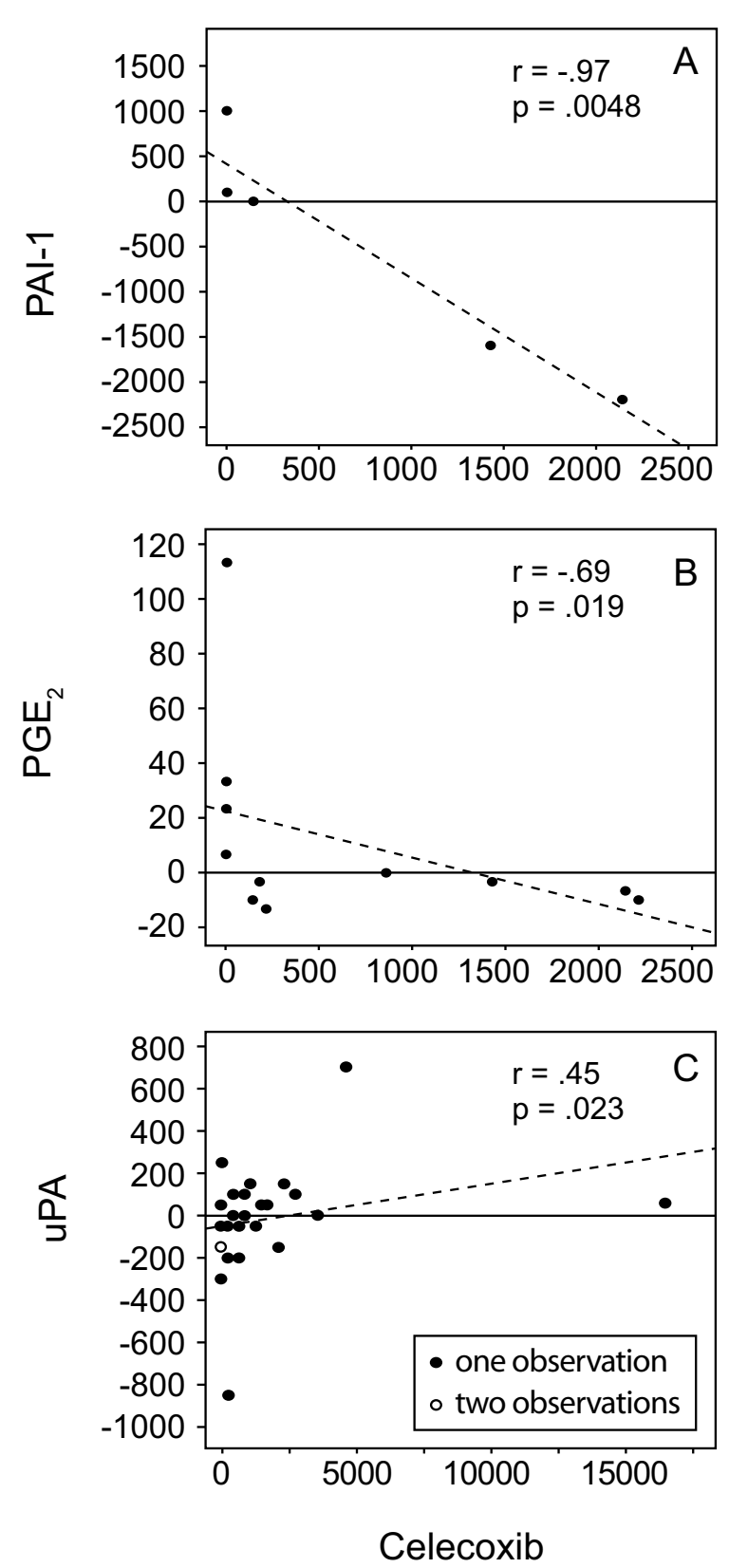

Figure I

Celecoxib concentration predicts on biomarker change. In women taking celecoxib $400 \mathrm{mg}$ bid, the change in PAI-I (pg/mg) (A) and $\mathrm{PGE}_{2}(\mathrm{ng} / \mathrm{mL})(B)$ in NAF and uPA $(\mathrm{pg} / \mathrm{mL})(\mathrm{C})$ in plasma correlated with celecoxib concentration $(\mathrm{ng} / \mathrm{mL})$.

\section{Authors' contributions}

ERS designed the study, enrolled subjects, and performed the majority of manuscript preparation. WQ and WZ conducted uPA, PAI-1 and PGE 2 analyses. JEH performed the statistical analyses, GR and YCC conducted the celecoxib analyses. FM and JTF assisted with manuscript preparation and critique. BK assisted with manuscript preparation and data gathering. All authors read and approved the final manuscript.

\section{Acknowledgements}

Funding was provided through Department of Defense grant DAMDI7-0II-0427. Funding for celecoxib plasma analysis was provided by Pfizer Corp, New York, NY.

\section{References}

I. Vassalli JD, Baccino D, Belin D: A cellular binding site for the $\mathbf{M r}$ $\mathbf{5 5 , 0 0 0}$ form of the human plasminogen activator, urokinase. J Cell Biol 1985, I00(I):86-92.

2. Ellis $\mathrm{V}$, Behrendt N, Dano K: Plasminogen activation by receptor-bound urokinase. A kinetic study with both cell-associated and isolated receptor. J Biol Chem 1991, 266(19): I 2752-12758.

3. Duffy MJ: Urokinase plasminogen activator and its inhibitor, PAI-I, as prognostic markers in breast cancer: from pilot to level I evidence studies. Clinical chemistry 2002, 48(8): | | 94- I I 97.

4. Andreasen PA, Kjoller L, Christensen L, Duffy MJ: The urokinasetype plasminogen activator system in cancer metastasis: a review. Int J Cancer I997, 72(I): I-22.

5. Ma Z, Webb DJ, Jo M, Gonias SL: Endogenously produced urokinase-type plasminogen activator is a major determinant of the basal level of activated ERK/MAP kinase and prevents apoptosis in MDA-MB-23 I breast cancer cells. J Cell Sci 200I, I | 4(Pt I 8):3387-3396.

6. Merchan JR, Chan B, Kale S, Schnipper LE, Sukhatme VP: In vitro and in vivo induction of antiangiogenic activity by plasminogen activators and captopril. J Natl Cancer Inst 2003, 95(5):388-399.

7. Chappuis PO, Dieterich B, Sciretta V, Lohse C, Bonnefoi H, Remadi S, Sappino AP: Functional evaluation of plasmin formation in primary breast cancer. J Clin Oncol 200 I, I 9( I 0):273 I-2738.

8. Merchan JR, Tang J, Hu G, Lin Y, Mutter W, Tong C, Karumanchi SA, Russell S], Sukhatme VP: Protease activity of urokinase and tumor progression in a syngeneic mammary cancer model. J Natl Cancer Inst 2006, 98(I I):756-764.

9. Blasi F: Proteolysis, cell adhesion, chemotaxis, and invasiveness are regulated by the u-PA-u-PAR-PAI-I system. Thromb Haemost 1999, 82(2):298-304.

10. Bajou K, Noel A, Gerard RD, Masson V, Brunner N, Holst-Hansen C, Skobe M, Fusenig NE, Carmeliet P, Collen D, et al.: Absence of host plasminogen activator inhibitor I prevents cancer invasion and vascularization. Nat Med 1998, 4(8):923-928.

II. Bajou K, Masson V, Gerard RD, Schmitt PM, Albert V, Praus M, Lund LR, Frandsen TL, Brunner N, Dano K, et al:: The plasminogen activator inhibitor PAI-I controls in vivo tumor vascularization by interaction with proteases, not vitronectin. Implications for antiangiogenic strategies. J Cell Biol 200I, I 52(4):777-784.

12. Ballabh P, Xu H, Hu F, Braun A, Smith K, Rivera A, Lou N, Ungvari Z, Goldman SA, Csiszar A, et al.: Angiogenic inhibition reduces germinal matrix hemorrhage. Nat Med 2007, I3(4):477-485.

I3. Chuang YH, Chuang WL, Huang SP, Huang CH: Cyclooxygenase-2 inhibitor ameliorates ureteric damage in rats with obstructed uropathy. Eur J Pharmacol 2007, 569(I-2): I 26- I 37.

14. Lanza-Jacoby S, Miller S, Flynn J, Gallatig K, Daskalakis C, Masferrer JL, Zweifel BS, Sembhi H, Russo IH: The cyclooxygenase-2 inhibitor, celecoxib, prevents the development of mammary tumors in Her-2/neu mice. Cancer Epidemiol Biomarkers Prev 2003, I 2( I 2): |486- |49|.

15. Basu GD, Pathangey LB, Tinder TL, Lagioia M, Gendler SJ, Mukherjee $P$ : Cyclooxygenase-2 inhibitor induces apoptosis in breast cancer cells in an in vivo model of spontaneous metastatic breast cancer. Mol Cancer Res 2004, 2(I I):632-642.

16. Sauter ER, Qin W, Schlatter L, Hewett JE, Flynn JT: Celecoxib decreases prostaglandin E2 concentrations in nipple aspirate fluid from high risk postmenopausal women and women with breast cancer. BMC Cancer 2006, 6:248.

17. Andrews HN, Habibi G, Kucab JE, Dunn SE: Celecoxib inhibits urokinase-type plasminogen activator (UPA) production in 
MDA-MB-23 I breast cancer cells. Breast cancer research and treatment 2005, 94(I):47-52.

18. Sauter ER, Qin W, Hewett JE, Ruhlen RL, Flynn JT, Rottinghaus G, Chen YC: Celecoxib concentration predicts decrease in prostaglandin E2 concentrations in nipple aspirate fluid from high risk women. $B M C$ cancer 2008, 8:49.

19. Sauter ER, Daly M, Linahan K, Ehya H, Engstrom PF, Bonney G, Ross EA, Yu H, Diamandis E: Prostate-specific antigen levels in nipple aspirate fluid correlate with breast cancer risk. Cancer Epidemiol Biomarkers Prev 1996, 5( I 2):967-970.

20. Sauter ER, Ross E, Daly M, Klein-Szanto A, Engstrom PF, Sorling A, Malick J, Ehya $\mathrm{H}$ : Nipple aspirate fluid: a promising non-invasive method to identify cellular markers of breast cancer risk. $\mathrm{Br}$ J Cancer 1997, 76(4):494-50I.

2I. Schonberger F, Heinkele G, Murdter TE, Brenner S, Klotz U, Hofmann U: Simple and sensitive method for the determination of celecoxib in human serum by high-performance liquid chromatography with fluorescence detection. J Chromatogr $B$ Analyt Technol Biomed Life Sci 2002, 768(2):255-260.

22. Qin W, Zhu W, Wagner-Mann C, Folk W, Sauter ER: Association of UPA, PAT-I, and UPAR in nipple aspirate fluid (NAF) with breast cancer. Cancer journal (Sudbury, Mass) 2003, 9(4):293-30I.

23. Ploplis VA, Tipton $\mathrm{H}$, Menchen $\mathrm{H}$, Castellino FJ: A urokinase-type plasminogen activator deficiency diminishes the frequency of intestinal adenomas in ApcMin/+ mice. The Journal of pathology 2007, 213(3):266-274.

24. Duffy MJ, Reilly D, McDermott E, O'Higgins N, Fennelly JJ, Andreasen PA: Urokinase plasminogen activator as a prognostic marker in different subgroups of patients with breast cancer. Cancer 1994, 74(8):2276-2280.

\section{Pre-publication history}

The pre-publication history for this paper can be accessed here:

http://www.biomedcentral.com/1471-2407/8/298/pre pub

Publish with Biomed Central and every scientist can read your work free of charge

"BioMed Central will be the most significant development for disseminating the results of biomedical research in our lifetime. "

Sir Paul Nurse, Cancer Research UK

Your research papers will be:

- available free of charge to the entire biomedical community

- peer reviewed and published immediately upon acceptance

- cited in PubMed and archived on PubMed Central

- yours - you keep the copyright 